\title{
BMJ Open Alcohol-related hospitalisations of trauma patients in Southern Taiwan: a cross-sectional study based on a trauma registry system
}

\author{
Cheng-Shyuan Rau, ${ }^{1}$ Hang-Tsung Liu, ${ }^{2}$ Shiun-Yuan Hsu, ${ }^{2}$ Tzu-Yu Cho, ${ }^{2}$ \\ Ching-Hua Hsieh ${ }^{2}$
}

To cite: Rau C-S, Liu H-T, Hsu S-Y, et al. Alcoholrelated hospitalisations of trauma patients in Southern Taiwan: a cross-sectional study based on a trauma registry system. BMJ Open 2014:4:e005947. doi:10.1136/bmjopen-2014005947

- Prepublication history for this paper is available online. To view these files please visit the journal online (http://dx.doi.org/10.1136/ bmjopen-2014-005947).

Received 6 July 2014 Revised 13 October 2014 Accepted 15 October 2014

CrossMark

\footnotetext{
${ }^{1}$ Department of Neurosurgery, Kaohsiung Chang Gung Memorial Hospital and Chang Gung University College of Medicine, Kaohsiung City, Taiwan

2Department of Trauma Surgery, Kaohsiung Chang Gung Memorial Hospital and Chang Gung University College of Medicine, Kaohsiung City, Taiwan
}

Correspondence to Dr Ching-Hua Hsieh; m93chinghua@gmail.com

\section{ABSTRACT}

Objectives: To provide an overview of the demographic characteristics of patients with positive blood alcohol concentration (BAC) and to investigate the performance of brain CT scans in these patients.

Design: Cross-sectional study.

Setting: Taiwan.

Participants: 2192 patients who had undergone a test for blood alcohol of 13233 patients registered in the Trauma Registry System between 1 January 2009 and 31 December 2012. A BAC level of $50 \mathrm{mg} / \mathrm{dL}$ was defined as the cut-off value. Detailed information was retrieved from the patients with positive BAC $(n=793)$ and was compared with information from those with a negative BAC $(n=1399)$.

Main outcome measures: Glasgow Coma Scale (GCS) and Injury Severity Score (ISS) as well as the performance and findings of obtained brain CT scans. Results: Patients with positive BAC had a higher rate of face injury, but a lower GCS score, a lower rate of head and neck injury, a lower ISS and New Injury Severity Score. Alcohol use was associated with a shorter length of hospital stay (8.6 vs 11.4 days, $p=0.000$ ) in patients with an ISS of $<16$. Of 496 patients with positive BAC who underwent brain $\mathrm{CT}$, $164(33.1 \%)$ showed positive findings on CT scan. In contrast, of 891 patients with negative BAC who underwent brain CT, 389 (43.7\%) had positive findings on CT scan. The lower percentage of positive CT scan findings in patients with positive BAC was particularly evident in patients with an ISS $<16(18.0 \%$ vs $28.8 \%$, $p=0.001$ ).

Conclusions: Patients who consumed alcohol tended to have a low GCS score and injuries that were less severe. However, given the significantly low percentage of positive findings, brain CT might be overused in these patients with less severe injuries.

\section{BACKGROUND}

Alcohol abuse and dependence are leading risk factors for injury. ${ }^{1}$ Alcohol at doses as low as $10-40 \mathrm{mg} / \mathrm{dL}$ can impair driving
Strengths and limitations of this study

- Trauma patients with alcoholic intoxication had different characteristics regarding injury areas, Glasgow Coma Scale score and severity of injury than those who had negative blood alcohol concentration (BAC).

- In patients with an Injury Severity Score of $<16$, alcohol intoxication is associated with a shorter length of hospital stay and a lower likelihood of positive findings on brain CT.

- The use of psychoactive drugs in addition to alcohol was not analysed and may be a confounding factor.

- The patients took a breathalyser test confirming the presence of alcohol, but no actual BAC test was performed, raising the possibility that some patients may have been entered into the wrong group for subsequent analysis, which could have led to selection bias.

performance, ${ }^{2}$ and the risk of being involved in a fatal accident increases exponentially with the driver's blood alcohol concentration (BAC). ${ }^{3}$ Studies have consistently demonstrated that risky drinking is strongly associated with a higher frequency of emergency department visits and hospitalisation. ${ }^{4} 5$ In the USA, more than 28000 accidental deaths per year are attributed to alcohol intake ${ }^{6}$ and 1.4 million emergency department injury visits are alcohol related. ${ }^{7}$

Acute alcohol intoxication often complicates the medical work-up required to rule out a potential undetected injury. If a depressed level of consciousness in a patient with traumatic brain injury is mistakenly attributed to alcohol intoxication, urgently needed diagnostic and therapeutic interventions may be delayed. However, if alcohol intoxication results in an overestimation of the severity of traumatic brain injury, more advanced techniques such as serial CT or 
more invasive procedures such as intracranial pressure monitor insertion may be unnecessarily performed ${ }^{4}$; there could also be unwarranted intensive care unit (ICU) admissions. ${ }^{8}$ It was previously proposed that significant alterations in the state of consciousness of trauma patients are predominantly a result of factors other than alcohol use. ${ }^{8}$ These factors may include head injuries, extracranial injuries, shock, hypothermia or concomitant use of central nervous system depressants in the form of medication or illicit drugs. ${ }^{8}$ Therefore, some researchers have proposed that a positive BAC should not be considered a sufficient reason to delay procedures such as brain CT or to modify treatment plans. ${ }^{89}$

Physicians cannot always rely on the responses of an intoxicated patient to questions asked during medical evaluations. There is no reliable method to determine whether an individual patient with an altered mental state is a chronic drinker with tolerance to alcohol. In addition, it is unlikely that a drinking history can be obtained or relied on in this clinical situation. It is also important to consider whether physicians may be under undue pressure and may perform CT scans simply to avoid the risk of errors or litigation. In this study, we aimed to provide an overview of the demographic and injury-related characteristics of patients with positive $\mathrm{BAC}$ and to investigate the performance and results of brain CT between groups of trauma patients classified as having positive or negative BAC.

\section{METHODS}

\section{Study design}

The study was conducted at Kaohsiung Chang Gung Memorial Hospital, a 2400-bed facility and Level I regional trauma centre that provides care to trauma patients primarily from the southern region of Taiwan. The Chang Gung Medical Foundation Institutional Review Board (IRB) approved this study before it was started (approval number 103-0418B). An informed consent was waived according to the regulations of the IRB. A retrospective study was designed to review all patients whose data were entered into the Trauma Registry System between 1 January 2009 and 31 December 2012. Of 13233 registered patients, 2192 (16.6\%) underwent a BAC test. Patients who did not undergo the BAC test were excluded from the study. According to the law of Taiwan, an alcohol test is systematically required for those in a traffic accident who had possibly consumed alcohol. Detailed patient information was retrieved from the Trauma Registry System of our institution, which included the following variables: age, gender, vital signs on admission, arrival time, injury mechanism, helmet-wearing status of motorcycle riders, BAC levels on arrival, Glasgow Coma Scale (GCS), Abbreviated Injury Scale (AIS) of each body region, Injury Severity Score (ISS), New Injury Severity Score (NISS), Trauma-Injury Severity Score (TRISS), performance of brain CT, CT-documented injuries, length of hospital stay (LOS), length of ICU stay (LICUS) and in-hospital mortality. The severity of head injuries was graded according to the AIS, a strictly anatomic measure of the severity of injury. A value of 0 was assigned to those without injury to the head region. The first GCS score recorded in the emergency department was used in the analysis to minimise the time for alcohol metabolism.

A BAC level of $50 \mathrm{mg} / \mathrm{dL}$ was defined as the cut-off value, the legal limit for drivers in Taiwan. Therefore, a BAC level of $50 \mathrm{mg} / \mathrm{dL}$ or higher at the time of arrival to the hospital was considered to define intoxication, and these patients were included in the further analysis. Patients who underwent a BAC test $(n=2192,16.6 \%)$ were compared with those did not receive a BAC test $(\mathrm{n}=11041,83.4 \%)$. Patients with a positive BAC $(\mathrm{n}=793$, $36.2 \%)$ were compared with those with a negative BAC $(\mathrm{n}=1399,63.8 \%)$ using SPSS V.20 statistical software (IBM) for statistical analysis. Where applicable, Pearson's $\chi^{2}$ test, the Fisher exact test or an independent Student $\mathrm{t}$ test was performed. We adopted a logistic regression approach to evaluate the association between BAC and the binary outcomes of performing brain CT. All results are presented as the mean \pm SE. A p value less than 0.05 was considered to be statistically significant.

\section{RESULTS}

The mean age of patients with negative and positive BAC was 41 years (table 1 ). On stratification by age (by decade), positive $\mathrm{BAC}$ was more frequent among patients aged 30-49 years and negative BAC was less frequent among those aged 10-19 years and $>60$ years. Of the 793 patients with positive BAC, $88 \% \quad(\mathrm{n}=698)$ were men and $12 \% \quad(n=95)$ were women. Of the 1,399 patients with negative BAC, $71.2 \%(\mathrm{n}=996)$ were men and $28.8 \% \quad(n=403)$ were women. Positive BAC was significantly associated with sex and the time of arrival. Most patients with positive BAC arrived between 23:00 and 7:00 $(\mathrm{n}=329,41.5 \%)$, and most patients with negative BAC arrived between 7:00 and 17:00 $(\mathrm{n}=636$, $45.5 \%)$. With regard to the mechanism of injury, most injured patients were drivers of motorcycles: 64.3\% $(\mathrm{n}=510)$ patients with positive BAC and $66.1 \% \quad(\mathrm{n}=925)$ of patients with negative BAC. Analysis of the data regarding helmet-wearing status, which were recorded for $95.2 \%$ of the motorcycle riders with negative BAC and $95.3 \%$ of the motorcycle riders with positive BAC, revealed that alcohol consumption in motorcycle riders was associated with a lower frequency of wearing a helmet; there were significantly more motorcycle riders with negative BAC wearing a helmet compared with the motorcycle riders with positive BAC. Unlike reports on studies in western countries, only $5.5 \% \quad(n=44)$ of patients with positive BAC and $3.6 \% \quad(\mathrm{n}=50)$ of those with negative BAC were drivers of motor vehicles. The mean BAC levels of injured patients admitted to a trauma centre with negative $\mathrm{BAC}$ and positive $\mathrm{BAC}$ were 
Table 1 Demographics of patients with positive and negative BAC

\begin{tabular}{|c|c|c|c|}
\hline Variable & $\begin{array}{l}\mathrm{BAC}-, \mathrm{n}(\%) \\
\mathrm{N}=1399\end{array}$ & $\begin{array}{l}\mathrm{BAC}+, \mathrm{n}(\%) \\
\mathrm{N}=793\end{array}$ & p Value \\
\hline Age & $41 \pm 19$ & $41 \pm 13$ & 0.256 \\
\hline \multicolumn{4}{|l|}{ Age category } \\
\hline $0-9$ years & $2(0.1)$ & $0(0.0)$ & 0.287 \\
\hline $10-19$ years & $205(14.7)$ & $16(2.0)$ & 0.000 \\
\hline 20-29 years & $290(20.7)$ & $166(20.9)$ & 0.910 \\
\hline $30-39$ years & 186 (13.3) & $200(25.2)$ & 0.000 \\
\hline 40-49 years & $196(14.0)$ & $214(27.0)$ & 0.000 \\
\hline 50-59 years & $249(17.8)$ & $140(17.7)$ & 0.932 \\
\hline$\geq 60$ years & $271(19.4)$ & $57(7.2)$ & 0.000 \\
\hline Gender & & & 0.000 \\
\hline Male & $996(71.2)$ & $698(88.0)$ & \\
\hline Female & $403(28.8)$ & $95(12.0)$ & \\
\hline \multicolumn{4}{|l|}{ Time } \\
\hline 7:00-17:00 & $636(45.5)$ & 147 (18.5) & 0.000 \\
\hline 17:00-23:00 & 436 (31.2) & 314 (39.6) & 0.000 \\
\hline 23:00-7:00 & $323(23.1)$ & $329(41.5)$ & 0.000 \\
\hline \multicolumn{4}{|l|}{ Mechanism } \\
\hline Driver of MV & $50(3.6)$ & $44(5.5)$ & \\
\hline Passenger of MV & $23(1.6)$ & $9(1.1)$ & \\
\hline Driver of motorcycle & $925(66.1)$ & $510(64.3)$ & \\
\hline Passenger of motorcycle & $59(4.2)$ & $20(2.5)$ & \\
\hline Bicycle & $48(3.4)$ & $23(2.9)$ & \\
\hline Pedestrian & $36(2.6)$ & $15(1.9)$ & \\
\hline Unspecific & $258(18.4)$ & $172(21.7)$ & \\
\hline \multicolumn{4}{|l|}{ Helmet (motorcycle riders) } \\
\hline Yes & $741(80.1)$ & $369(72.4)$ & 0.001 \\
\hline No & $140(15.1)$ & $117(22.9)$ & 0.000 \\
\hline Unknown & $44(4.8)$ & $24(4.7)$ & 0.965 \\
\hline \multicolumn{4}{|l|}{ BAC level (mg/dL) } \\
\hline Mean & 6.4 & 192.3 & \\
\hline Range & $0-49$ & $50-443$ & \\
\hline
\end{tabular}

$6.4 \mathrm{mg} / \mathrm{dL}$ (range $0-49 \mathrm{mg} / \mathrm{dL}$ ) and $192.3 \mathrm{mg} / \mathrm{dL}$ (range 50-443 mg/dL), respectively. The mean BAC level among patients with positive BAC was nearly four times the limit legally permitted for driving.

When compared with the patients who did not have an alcohol test, the patients who had undergone an alcohol test presented a significantly lower GCS score $(14.7 \pm 1.4$ vs $12.7 \pm 3.8, \mathrm{p}=0.000)$, with the difference being more than 1 point (table 2). The incidence of unclear consciousness (GCS score 8 or less) and of a GCS score of 9-12 was significantly higher in the patients who had undergone an alcohol test. The percentage of patients with a GCS score of 13 or greater was significantly higher among those without an alcohol test. On the basis of the AIS, patients who had undergone an alcohol test had a higher rate of injuries to the head/neck, face, thorax and abdomen; in contrast, patients who did not have an alcohol test had a higher rate of injury to an extremity. The patients who underwent an alcohol test were associated with a higher ISS (13.2 \pm 10.0 vs $7.1 \pm 5.5, \mathrm{p}=0.000)$, NISS $(15.0 \pm 11.1$ vs 7.9 $\pm 6.2, \mathrm{p}=0.000)$, a lower TRISS $(0.92 \pm 0.18$ vs $0.97 \pm 0.08$, $\mathrm{p}=0.000)$ and higher in-hospital mortality $(4.3 \%$ vs $1.0 \%$, $\mathrm{p}=0.000)$. In addition, the GCS score was significantly lower among patients with positive BAC than among those with negative $\mathrm{BAC}(12.4 \pm 3.8$ vs $12.8 \pm 3.7, \mathrm{p}=0.020)$; however, the difference was less than 1 point (table 2). The incidence of unclear consciousness (GCS score 8 or less) was not significant in patients with either positive or negative BAC $(\mathrm{p}=0.228)$. The percentage of patients with a GCS score of 9-12 was significantly higher among patients with positive BAC $(p=0.019)$. In contrast, the percentage of patients with a GCS score of 13 or greater was significantly higher among those with negative BAC. On the basis of the AIS, patients with positive BAC had a higher rate of facial injury $(40.5 \%$ vs $31.9 \%$; $=0.000)$ than those with negative BAC. In contrast, patients with negative BAC had a higher rate of head and neck injuries $(58.8 \%$ vs $52.7 \%$; $=0.005)$. However, the frequencies of injuries to the thorax, abdomen and extremities, were not significantly different between the groups. Alcohol consumption was associated with a lower ISS $(12.1 \pm 10.0$ vs $13.7 \pm 10.0, \mathrm{p}=0.000)$ and NISS $(13.8$ \pm 11.0 vs $15.7 \pm 11.0, \mathrm{p}=0.000)$, but not with TRISS $(0.93$ \pm 0.17 vs $0.92 \pm 0.18, \mathrm{p}=0.236)$ or in-hospital mortality $(3.7 \%$ vs $4.6 \%, \mathrm{p}=0.272)$. To ascertain the effects of 
Table 2 GCS and injury-related characteristics of the patients who had and had not undergone an alcohol test as well as of the patients with positive and negative BAC

\begin{tabular}{|c|c|c|c|c|}
\hline \multicolumn{5}{|c|}{ Patients who did not have a BAC test vs patients who had undergone a BAC Test } \\
\hline Variables & & $\begin{array}{l}\text { No BAC test } \\
\mathrm{N}=11041\end{array}$ & $\begin{array}{l}\text { BAC test } \\
\mathrm{N}=2192\end{array}$ & p Value \\
\hline GCS, n (\%) & & $14.7 \pm 1.4$ & $12.7 \pm 3.8$ & 0.000 \\
\hline$\leq 8$ & & $186(1.7)$ & $378(17.2)$ & 0.000 \\
\hline$\overline{9}-12$ & & $211(1.9)$ & 247 (11.3) & 0.000 \\
\hline$\geq 13$ & & $10644(96.4)$ & $1567(71.5)$ & 0.000 \\
\hline \multicolumn{5}{|l|}{ AIS, $n(\%)$} \\
\hline Head/neck & & $1981(17.9)$ & 1241 (56.6) & 0.000 \\
\hline Face & & 1312 (11.9) & 767 (35.0) & 0.000 \\
\hline Thorax & & $989(9.0)$ & 442 (20.2) & 0.000 \\
\hline Abdomen & & $542(4.9)$ & 282 (12.9) & 0.000 \\
\hline Extremity & & 8235 (74.6) & $1292(58.9)$ & 0.000 \\
\hline ISS & & $7.1 \pm 5.5$ & $13.2 \pm 10.0$ & 0.000 \\
\hline NISS & & $7.9 \pm 6.2$ & $15.0 \pm 11.1$ & 0.000 \\
\hline TRISS & & $0.97 \pm 0.08$ & $0.92 \pm 0.18$ & 0.000 \\
\hline \multicolumn{2}{|l|}{ Mortality, n (\%) } & $107(1.0)$ & $94(4.3)$ & 0.000 \\
\hline Variable & & $\begin{array}{l}\mathrm{BAC}- \\
\mathrm{N}=1399\end{array}$ & $\begin{array}{l}\text { BAC+ } \\
N=793\end{array}$ & p Value \\
\hline GCS, n (\%) & & $12.8 \pm 3.7$ & $12.4 \pm 3.8$ & 0.020 \\
\hline$\leq 8$ & & $231(16.5)$ & 147 (18.5) & 0.228 \\
\hline $9-12$ & & $141(10.1)$ & $106(13.4)$ & 0.019 \\
\hline$\geq 13$ & & $1027(73.4)$ & $540(68.1)$ & 0.008 \\
\hline \multicolumn{5}{|l|}{ AIS, n (\%) } \\
\hline Head/neck & & $823(58.8)$ & $418(52.7)$ & 0.005 \\
\hline Face & & 446 (31.9) & $321(40.5)$ & 0.000 \\
\hline Thorax & & 283 (20.2) & 159 (20.1) & 0.920 \\
\hline Abdomen & & 184 (13.2) & $98(12.4)$ & 0.594 \\
\hline Extremity & & $826(59)$ & 467 (58.9) & 0.945 \\
\hline ISS & & $13.7 \pm 10.0$ & $12.1 \pm 10.0$ & 0.000 \\
\hline TRISS & & $0.92 \pm 0.18$ & $0.93 \pm 0.17$ & 0.236 \\
\hline NISS & & $15.7 \pm 11.0$ & $13.8 \pm 11.0$ & 0.000 \\
\hline Mortality, n (\%) & & $65(4.6)$ & $29(3.7)$ & 0.272 \\
\hline \multicolumn{5}{|l|}{ AIS-head/neck } \\
\hline & ISS & $\begin{array}{l}\mathrm{BAC}- \\
\mathrm{N}=823\end{array}$ & $\begin{array}{l}\mathrm{BAC}+ \\
\mathrm{N}=418\end{array}$ & p Value \\
\hline \multirow[t]{3}{*}{ n (\%) } & $<16$ & 345 (41.9) & $201(48.1)$ & 0.039 \\
\hline & $16-24$ & $316(38.4)$ & $152(36.4)$ & 0.485 \\
\hline & $\geq 25$ & 162 (19.7) & 65 (15.5) & 0.075 \\
\hline \multirow[t]{4}{*}{ GCS } & total & $11.6 \pm 4.2$ & $10.9 \pm 4.3$ & 0.004 \\
\hline & $<16$ & $13.3 \pm 3.1$ & $12.2 \pm 3.6$ & 0.001 \\
\hline & $16-24$ & $11.5 \pm 4.1$ & $10.8 \pm 4.0$ & 0.079 \\
\hline & $\geq 25$ & $8.3 \pm 4.7$ & $6.7 \pm 4.5$ & 0.023 \\
\hline
\end{tabular}

AIS, Abbreviated Injury Scale; BAC, blood alcohol concentration; GCS, Glasgow Coma Scale; ISS, Injury Severity Score; NISS, New Injury Severity Score; TRISS, Trauma- Injury Severity Score.

head injury and the severity of the injury on the calculation of the GCS score, we stratified patients with an AIS of 1-5 in the head and neck region according to ISS. An ISS of $<16$ was more common among patients with positive BAC ( $48.1 \%$ vs $41.9 \%, \mathrm{p}=0.039)$, and GCS scores differed significantly between head injury patients with positive and negative BAC $(10.9 \pm 4.3$ vs $11.6 \pm 4.2$, $\mathrm{p}=0.004)$; however, the difference was still less than 1 point. GCS scores were significantly different (difference of more than 1 point) between patients with positive and negative $\mathrm{BAC}$ in the subgroup of patients with an ISS of $<16(12.2 \pm 3.6$ vs $13.3 \pm 3.1, p=0.001)$ or $\geq 25(6.7$ \pm 4.5 vs $8.3 \pm 4.7, \mathrm{p}=0.023)$.

On stratification of patients according to ISS $(<16,16-$ 24 and $\geq 25$ ), an ISS of $<16$ was more common among patients with positive BAC ( 68.0 vs $60.6, \mathrm{p}=0.001$ ) and an ISS of $16-24$ (26.2 vs 22.0, $\mathrm{p}=0.033$ ) or $\geq 25$ (13.2 vs 10.0 , $\mathrm{p}=0.024$ ) was more common among patients with negative BAC (table 3). Alcohol use was associated with a shorter LOS (8.6 vs 11.4 days, $\mathrm{p}=0.000$ ) among patients 
with an ISS of $<16$. LOS did not differ significantly between patients with positive and negative BAC in the subgroup of more severely injured patients (ISS of 1624 or $\geq 25$ ). In addition, fewer patients with positive BAC were admitted to the ICU among patients with an ISS of $<16(9.6 \%$ vs $11.9 \%, \mathrm{p}=0.009)$ or $\geq 25(9.1 \%$ vs $10.7 \%$, $\mathrm{p}=0.033$ ). Alcohol use was not associated with LICUS, regardless of injury severity. Patients with positive and negative BAC did not have significantly different mortality rates, again, regardless of injury severity.

Brain CT was performed in 496 of 793 (62.5\%) patients with positive BAC and in 891 of 1399 (63.7\%) patients with negative BAC (table 4). The rate of brain CT performance was not significantly different between the two groups, irrespective of injury severity. Brain CT showed positive findings in 164 of the 496 (33.1\%) patients with positive $\mathrm{BAC}$ and in 389 of the 891 $(43.7 \%)$ patients with negative BAC. The percentage of positive findings was lower for patients with positive BAC $(p=0.000)$. This difference was attributed to the lower percentage of positive findings among patients with positive BAC who had an ISS of $<16(18.0 \%$ vs $28.8 \%$, $\mathrm{p}=0.001$ ). Consequently, the percentage of positive brain CT findings did not differ significantly between the two groups among more severely injured patients (ISS of 16-24 or $\geq 25$ ). Further, the proportion of patients with positive brain CT findings for the final diagnosis (subarachnoid haemorrhage, subdural haemorrhage, epidural haemorrhage and intracranial haemorrhage) did not differ between patients with positive and negative BAC. Binary logistic regression analysis was performed to evaluate the relationship between BAC and the performance of brain CT among patients with positive BAC. According to receiver operating characteristic curve analysis (figure 1), a BAC of $156 \mathrm{mg} / \mathrm{dL}$ was identified as the cut-off for the decision to perform brain CT, with an area under the curve of $0.562 \pm 0.021$ (95\% CI 0.521 to $0.603 ; \mathrm{p}=0.003$ ). However, the discriminating power was only slightly better than would be expected if left to chance.

\section{DISCUSSION}

In this study, we identified a relationship between a low GCS score and a low ISS, and alcohol consumption. Another significant finding was that, in patients with an ISS of $<16$, alcohol intoxication is associated with a shorter LOS and a lower likelihood of positive findings on brain CT.

The GCS is the most commonly used means of quantifying the level of consciousness and for clinical decisionmaking involving patients with traumatic brain injury in emergency departments. ${ }^{10}$ Although prior studies have demonstrated that alcohol consumption is associated with a lower average GCS score, ${ }^{11} 12$ studies of the impact of alcohol intoxication on the GCS score in trauma patients report conflicting results. Some studies have shown that alcohol consumption does not result in a clinically significant reduction in the GCS score of trauma patients. ${ }^{813}$ In a study of 108929 patients registered with the National Trauma Data Bank of the American College of Surgeons between 1994 and 2003, alcohol consumption does not influence the GCS score irrespective of the severity of traumatic brain injury. ${ }^{8}$ In addition, when stratified by anatomic severity of head injuries, alcohol consumption did not reduce the total GCS score or any of its components (eg, motor, speech and eye-opening) by more than 1 point in any group. ${ }^{8}$

Table 3 LOS and mortality rates in patients stratified by the ISS

\begin{tabular}{|c|c|c|c|c|c|}
\hline Variable & ISS & $\begin{array}{l}\text { BAC- } \\
\mathrm{N}=1399\end{array}$ & & $\begin{array}{l}\text { BAC+ } \\
\mathrm{N}=793\end{array}$ & $p$ Value \\
\hline \multicolumn{6}{|l|}{ Ward } \\
\hline \multirow[t]{3}{*}{ n (\%) } & $<16$ & $848(60.6)$ & & $539(68.0)$ & 0.001 \\
\hline & $16-24$ & 366 (26.2) & & $175(22.0)$ & 0.033 \\
\hline & $\geq 25$ & $185(13.2)$ & & $79(10.0)$ & 0.024 \\
\hline \multirow[t]{3}{*}{ LOS (days) } & $<16$ & $11.4 \pm 10.5$ & & $8.6 \pm 7.6$ & 0.000 \\
\hline & $16-24$ & $13.0 \pm 11.5$ & & $14.8 \pm 12$ & 0.182 \\
\hline & $\geq 25$ & $19.8 \pm 22.5$ & & $21.1 \pm 16$ & 0.652 \\
\hline \multicolumn{6}{|l|}{ ICU } \\
\hline \multirow[t]{3}{*}{ n (\%) } & $<16$ & 166 (11.9) & & 76 (9.6) & 0.009 \\
\hline & $16-24$ & 237 (16.9) & & $115(14.5)$ & 0.827 \\
\hline & $\geq 25$ & $149(10.7)$ & & $72(9.1)$ & 0.033 \\
\hline \multirow[t]{3}{*}{ LICUS (days) } & $<16$ & $5.8 \pm 7.4$ & & $4.5 \pm 3.5$ & 0.110 \\
\hline & $16-24$ & $7.5 \pm 7.3$ & & $6.7 \pm 8.0$ & 0.587 \\
\hline & $\geq 25$ & $13.3 \pm 20.2$ & & $12.8 \pm 13.3$ & 0.500 \\
\hline \multicolumn{6}{|l|}{ Mortality } \\
\hline \multirow[t]{3}{*}{ n (\%) } & $<16$ & 6 & (0.4) & $2(0.3)$ & 0.510 \\
\hline & $16-24$ & 17 & (1.2) & $7(0.9)$ & 0.472 \\
\hline & $\geq 25$ & 42 & (3.0) & $20(2.5)$ & 0.515 \\
\hline
\end{tabular}


Table 4 CT imaging performed to evaluate brain injuries

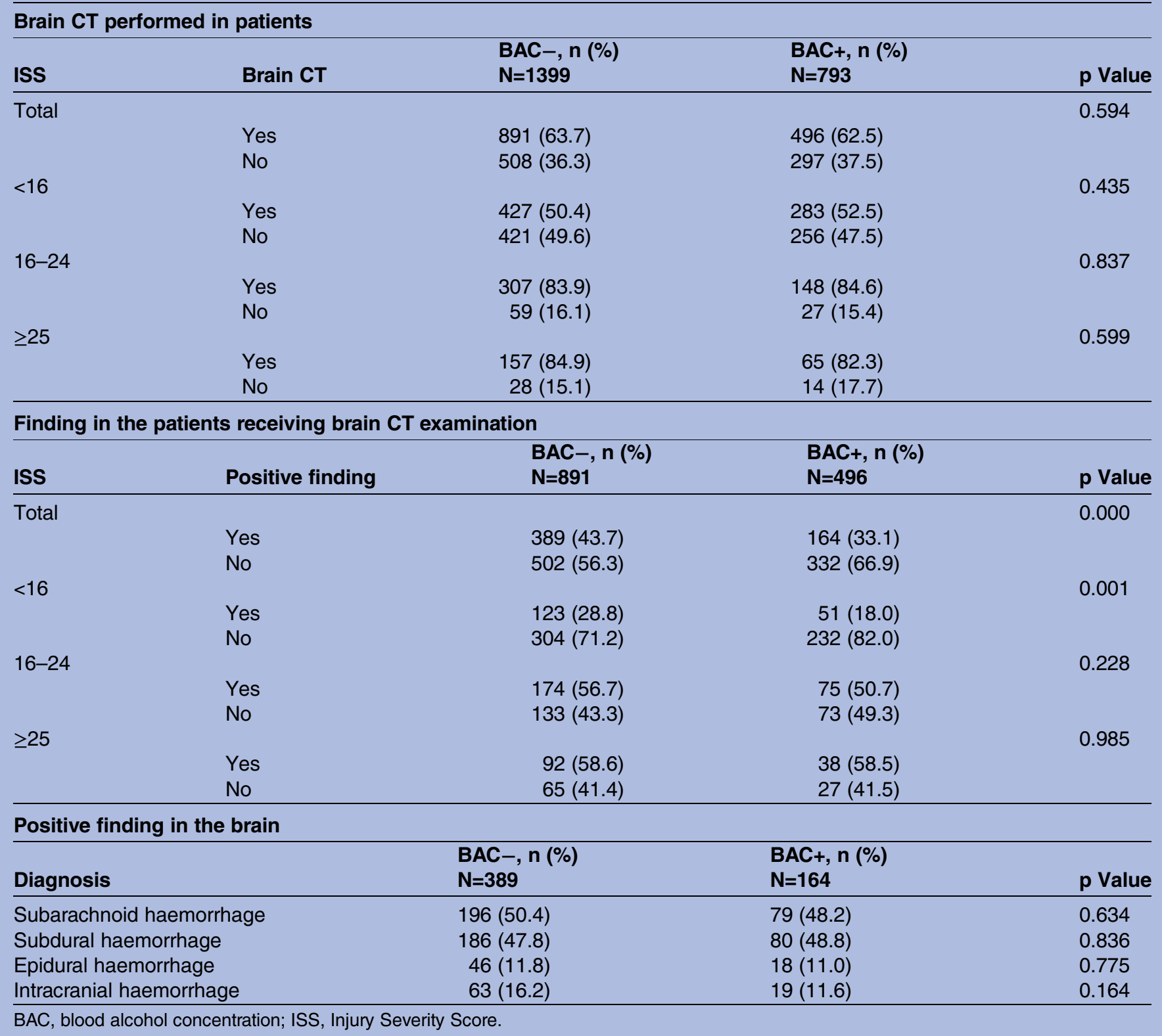

In this study, the patients who had undergone a BAC test had a significantly lower GCS score than those who did not have a BAC test and the difference was more than 1 point. In addition, the patients with positive BAC and those with positive BAC and head injuries had a significantly lower GCS score; however, the difference was less than 1 point. When stratified by the ISS, patients with positive BAC had a significantly lower GCS score by more than 1 point among patients with an ISS of $<16$ or $\geq 25$. Of note, the mean BAC of injured patients with a positive BAC admitted to a trauma centre is $192.3 \mathrm{mg}$ / $\mathrm{dL}$, a level nearly four times the limit legally permitted for driving in Taiwan and sufficient to induce tolerance in some patients. However, there is no reliable means with which to determine whether an altered mental status is characteristic of a chronic drinker with tolerance. These results support the assertion that injury severity had an impact on the observed level of consciousness and that significant alterations in the level of consciousness in trauma patients are predominantly a result of factors other than the consumption of alcohol alone. The safest strategy is to consider all mental status changes in trauma patients to be attributable to brain injury, rather than to alcohol consumption. ${ }^{8}$

Our results showed that patients who had undergone an alcohol test were associated with a higher ISS and NISS, a lower TRISS and higher in-hospital mortality. Besides, alcohol consumption was associated with a lower ISS and NISS, but did not effect a significant change in TRISS. The NISS is calculated as the sum of the squares of the three highest AIS scores regardless of the body region affected. ${ }^{14}$ Accordingly, a lower NISS accompanied by a lower ISS in this study was expected. In addition, the TRISS is calculated to determine the 


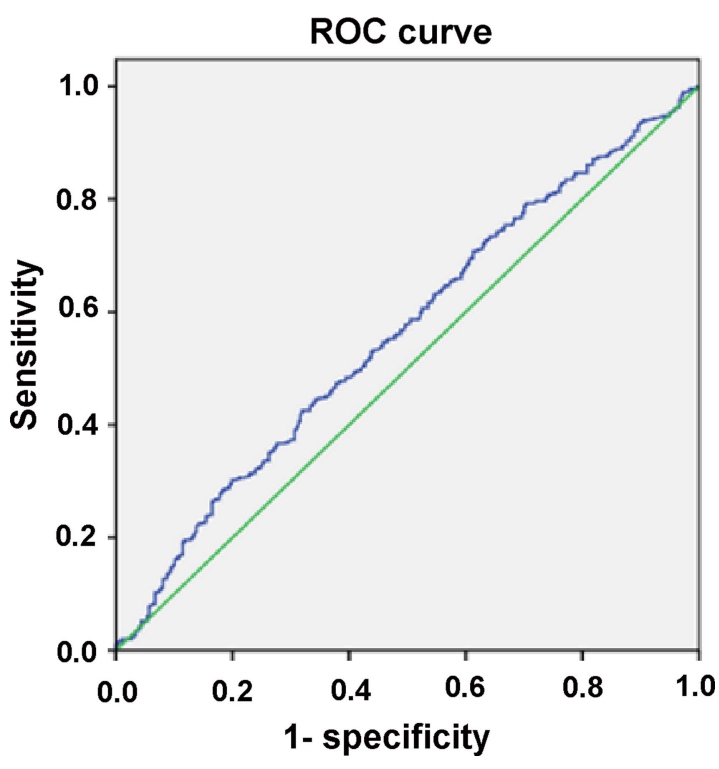

Figure 1 Receiver operating characteristic (ROC) curve analysis to identify the blood alcohol concentration cut-off level for performing brain CT.

probability of survival of patients from the ISS, ${ }^{15}$ blood pressure, respiratory rate, GCS score, age and mechanism of injury. This is also expected when the in-hospital mortality is similar in patients with positive and negative BAC. Also, patients who consumed alcohol before their injury were more likely to have suffered a facial injury but less likely to have suffered an injury to the critical regions of the head and neck. Additionally, patients with negative BAC had a higher frequency of traumatic brain injuries as identified by brain CT than those with positive BAC $(43.7 \%$ vs $33.1 \%, \mathrm{p}=0.000)$. Some studies have shown that serum ethanol is independently associated with increased ${ }^{16}{ }^{17}$ or decreased mortality in patients with traumatic brain injuries, ${ }^{18} 19$ while another study showed that the risk of mortality was not higher in patients with positive BAC, as was the case in our study as well. ${ }^{20}$ However, the observed associations of alcohol consumption with a lower ISS and a lower frequency of traumatic brain injury do not lead to the conclusion that alcohol consumption protected patients from sustaining severe injuries or traumatic brain injury. This is primarily because alcohol intoxication impairs one's motor skills, reaction time, and judgement, and as a result impacts one's ability to ride a motorcycle or drive a motor vehicle. The level of skill required to ride a motorcycle or drive a motor vehicle under the influence of the same concentration of alcohol should also be considered. In this study, motorcycle accidents comprised most of the mechanisms of injury, in contrast to prior studies that report alcohol-related traffic injuries to be primarily limited to motor vehicle drivers. ${ }^{21}$

With regard to the LOS, alcohol consumption was associated with a shorter LOS among patients with an ISS of $<16$. The negative association between the LOS and alcohol intoxication may be explained by the observation that an intoxicated patient has a higher chance of being hospitalised than a non-intoxicated patient, and subsequently of getting discharged once deemed to no longer be under the influence of alcohol. ${ }^{4}$ Another potential explanation for a shorter LOS among alcohol users could be an intense desire to consume alcohol while they are hospitalised, ${ }^{22}$ leading physicians to be more inclined to discharge them as soon as their medical condition permits, to prevent potential problems. ${ }^{22}$ Of note, in this study, the use of alcohol was not associated with the LICUS, regardless of the severity of injury.

It is reasonable to presume that many clinicians opt for brain CT in injured patients if they deem the physical examination results unreliable due to substance abuse. In this study, the rate of brain CT performance did not differ significantly between patients with positive or negative $\mathrm{BAC}$ and was not related to the final diagnosis (subarachnoid haemorrhage, subdural haemorrhage, epidural haemorrhage and intracranial haemorrhage), irrespective of injury severity. However, the percentage of patients with positive findings was lower among patients with positive BAC, particularly among those with an ISS of $<16$. Similar results have been reported, noting a relative risk of performing brain CT of 1.18 when trauma patients with an ISS of $<16$ are intoxicated. ${ }^{23}$ The results of this study also imply that alcohol intoxication in trauma patients may be associated with an unacceptable burden on hospital resources as well as an increased cost of healthcare.

This study has some limitations. First, the combination of psychoactive drugs and alcohol may further increase the risk of having an accident, ${ }^{24} 25$ and potential drug users may have refused to undertake drug tests, which may have led to a selection bias. However, in our study, this analytical bias is thought to be random. Second, although BAC measurement is the most commonly used method to determine whether trauma patients have consumed alcohol and all drivers involved in traffic accidents were compelled by law to undergo a test to estimate BAC, a few patients may have refused to undergo an actual BAC test after a breathalyser confirmed the presence of alcohol. Accordingly, such patients may be entered and analysed with the wrong group because the breathalyser results would not have been noted in the medical records; however, in our experience, such patients are rare. In addition, the lack of exact time from the injury to an alcohol test may result in a bias of the acquired data; however, according to Taiwan government data from January 2009 to June 2009 , the average transport time was about $12 \min ^{26}$ and from our yet published study, which demonstrated that the mean transport time of the patients transported by emergency medical service (EMS) to our hospital was $18.3 \pm 7.9 \mathrm{~min}$, the bias may be minimal. Finally, the lack of clear and strict indication for performing a brain CT examination in these intoxicated patients by the on-duty 
physicians in the emergency department may result in some bias in this study.

\section{CONCLUSION}

This study revealed that patients who consumed alcohol tended to have a lower GCS score and less severe injuries. Among those with an ISS of $<16$, alcohol intoxication was associated with a shorter LOS. Given the significantly low percentage of positive findings for alcohol consumption, brain CT may be overused in less severely injured patients.

Contributors CSR wrote the manuscript, HTL revised the manuscript, SYH and TYC carried out the analysis and edited the tables, $\mathrm{CHH}$ designed the study, contributed to the analysis and interpretation of data and drafted the manuscript. All authors read and approved the final manuscript.

Funding This research was supported by a grant from CDRPG8C0031. Competing interests None.

Ethics approval The Chang Gung Medical Foundation Institutional Review Board (approval number 103-0418B).

Provenance and peer review Not commissioned; externally peer reviewed.

Data sharing statement No additional data are available.

Open Access This is an Open Access article distributed in accordance with the Creative Commons Attribution Non Commercial (CC BY-NC 4.0) license, which permits others to distribute, remix, adapt, build upon this work noncommercially, and license their derivative works on different terms, provided the original work is properly cited and the use is non-commercial. See: http:// creativecommons.org/licenses/by-nc/4.0/

\section{REFERENCES}

1. Gentilello LM, Rivara FP, Donovan DM, et al. Alcohol interventions in a trauma center as a means of reducing the risk of injury recurrence. Ann Surg 1999;230:473-80; discussion 80-3

2. Ogden EJ, Moskowitz $\mathrm{H}$. Effects of alcohol and other drugs on driver performance. Traffic Inj Prev 2004;5:185-98.

3. Zador PL, Krawchuk SA, Voas RB. Alcohol-related relative risk of driver fatalities and driver involvement in fatal crashes in relation to driver age and gender: an update using 1996 data. J Stud Alcohol 2000;61:387-95.

4. Moore EE. Alcohol and trauma: the perfect storm. $J$ Trauma 2005;59 (Suppl 3):S53-6; discussion S67-75

5. McCaig LF, Nawar EW. National Hospital Ambulatory Medical Care Survey: 2004 emergency department summary. Adv Data 2006; (372):1-29.

6. Hingson RW, Zha W. Age of drinking onset, alcohol use disorders, frequent heavy drinking, and unintentionally injuring oneself and others after drinking. Pediatrics 2009;123:1477-84.
7. Gentilello LM, Ebel BE, Wickizer TM, et al. Alcohol interventions for trauma patients treated in emergency departments and hospitals: a cost benefit analysis. Ann Surg 2005;241:541-50.

8. Stuke L, Diaz-Arrastia R, Gentilello LM, et al. Effect of alcohol on Glasgow Coma Scale in head-injured patients. Ann Surg 2007;245:651-5.

9. Schermer CR, Gentilello LM, Hoyt DB, et al. National survey of trauma surgeons' use of alcohol screening and brief intervention. $J$ Trauma 2003;55:849-56.

10. Teasdale G, Jennett B. Assessment of coma and impaired consciousness. A practical scale. Lancet 1974;2:81-4.

11. Dultz LA, Frangos S, Foltin G, et al. Alcohol use by pedestrians who are struck by motor vehicles: how drinking influences behaviors medical management, and outcomes. $J$ Trauma 2011;71:1252-7.

12. Brickley MR, Shepherd JP. The relationship between alcohol intoxication, injury severity and Glasgow Coma Score in assault patients. Injury 1995;26:311-14.

13. Sperry JL, Gentilello LM, Minei JP, et al. Waiting for the patient to "sober up": Effect of alcohol intoxication on glasgow coma scale score of brain injured patients. J Trauma 2006:61:1305-11.

14. Tohira H, Jacobs I, Mountain D, et al. Systematic review of predictive performance of injury severity scoring tools. Scand $J$ Trauma Resusc Emerg Med 2012;20:63.

15. Lefering R. Trauma scoring systems. Curr Opin Crit Care 2012;18:637-40.

16. Pories SE, Gamelli RL, Vacek P, et al. Intoxication and injury J Trauma 1992;32:60-4.

17. Luna GK, Maier RV, Sowder L, et al. The influence of ethano intoxication on outcome of injured motorcyclists. J Trauma 1984:24:695-700

18. Salim A, Ley EJ, Cryer HG, et al. Positive serum ethanol level and mortality in moderate to severe traumatic brain injury. Arch Surg 2009:144:865-71.

19. Talving $P$, Plurad D, Barmparas $G$, et al. Isolated severe traumatic brain injuries: association of blood alcohol levels with the severity of injuries and outcomes. J Trauma 2010;68:357-62.

20. Hsieh CH, Su LT, Wang YC, et al. Does alcohol intoxication protect patients from severe injury and reduce hospital mortality? The association of alcohol consumption with the severity of injury and survival in trauma patients. Am Surg 2013;79:1289-94.

21. Brady JE, Baker SP, Dimaggio C, et al. Effectiveness of mandatory alcohol testing programs in reducing alcohol involvement in fatal motor carrier crashes. Am J Epidemiol 2009;170:775-82.

22. Roudsari B, Caetano R, Field C. Alcohol intoxication/dependence, ethnicity and utilisation of health care resources in a level I trauma center. Injury 2011;42:66-71.

23. Jurkovich GJ, Rivara FP, Gurney JG, et al. Effects of alcoho intoxication on the initial assessment of trauma patients. Ann Emerg Med 1992:21:704-8.

24. Ricci G, Majori S, Mantovani W, et al. Prevalence of alcohol and drugs in urine of patients involved in road accidents. J Prev Med Hyg 2008;49:89-95.

25. Bogstrand ST, Gjerde H, Normann PT, et al. Alcohol, psychoactive substances and non-fatal road traffic accidents-a case-control study. BMC Public Health 2012;12:734.

26. Hsiao KY, Lin LC, Chou MH, et al. Outcomes of trauma patients: direct transport versus transfer after stabilisation at another hospital. Injury 2012;43:1575-9. 